\title{
Pseudomonas putida as a potential biocontrol agent against Salmonella Java biofilm formation in the drinking water system of broiler houses
}

Sharon Maes ${ }^{1}$, Koen De Reu', Stephanie Van Weyenberg ${ }^{1}$, Bram Lories², Marc Heyndrickx ${ }^{1,3}$ and Hans Steenackers ${ }^{2^{*}}$ (i)

\begin{abstract}
Background: Environmental biofilms can induce attachment and protection of other microorganisms including pathogens, but can also prevent them from invasion and colonization. This opens the possibility for so-called biocontrol strategies, wherein microorganisms are applied to control the presence of other microbes. The potential for both positive and negative interactions between microbes, however, raises the need for in depth characterization of the sociobiology of candidate biocontrol agents (BCAs). The inside of the drinking water system (DWS) of broiler houses is an interesting niche to apply BCAs, because contamination of these systems with pathogens plays an important role in the infection of broiler chickens and consequently humans. In this study, Pseudomonas putida, which is part of the natural microbiota in the DWS of broiler houses, was evaluated as BCA against the broiler pathogen Salmonella Java.
\end{abstract}

Results: To study the interaction between these species, an in vitro model was developed simulating biofilm formation in the drinking water system of broilers. Dual-species biofilms of $P$. putida strains P1, P2, and P3 with S. Java were characterized by competitive interactions, independent of $P$. putida strain, $S$. Java inoculum density and application order. When equal inocula of S. Java and P. putida strains P1 or P3 were simultaneously applied, the interaction was characterized by mutual inhibition, whereas $P$. putida strain P2 showed an exploitation of S. Java. Lowering the inoculum density of $S$. Java changed the interaction with P. putida strain P3 also into an exploitation of S. Java. A further increase in S. Java inhibition was established by P. putida strain P3 forming a mature biofilm before applying $S$. Java.

Conclusions: This study provides the first results showing the potential of $P$. putida as BCA against $S$. Java in the broiler environment. Future work should include more complex microbial communities residing in the DWS, additional Salmonella strains as well as chemicals typically used to clean and disinfect the system.

Keywords: Biocontrol, Biofilm model, Drinking water system, Pseudomonas putida, Salmonella Java, Social interactions

\footnotetext{
* Correspondence: hans.steenackers@kuleuven.be

${ }^{2}$ Faculty of Bioscience Engineering, Department of Microbial and Molecular Systems (M2S), Centre of Microbial and Plant Genetics (CMPG), University of Leuven, Kasteelpark Arenberg 20 box 2460, 3001 Leuven, Belgium Full list of author information is available at the end of the article
}

(c) The Author(s). 2020 Open Access This article is licensed under a Creative Commons Attribution 4.0 International License, which permits use, sharing, adaptation, distribution and reproduction in any medium or format, as long as you give appropriate credit to the original author(s) and the source, provide a link to the Creative Commons licence, and indicate if changes were made. The images or other third party material in this article are included in the article's Creative Commons licence, unless indicated otherwise in a credit line to the material. If material is not included in the article's Creative Commons licence and your intended use is not permitted by statutory regulation or exceeds the permitted use, you will need to obtain permission directly from the copyright holder. To view a copy of this licence, visit http://creativecommons.org/licenses/by/4.0/ The Creative Commons Public Domain Dedication waiver (http://creativecommons.org/publicdomain/zero/1.0/) applies to the data made available in this article, unless otherwise stated in a credit line to the data. 


\section{Background}

Infections with Salmonella frequently occur in broiler chickens [14], leading to animal disease, animal death and large economic losses. Moreover, the consumption of contaminated poultry meat is a major source of human infections with Salmonella [3, 14]. Broiler chickens are mainly infected through environmental sources, feed and drinking water [26]. Drinking water quality and the drinking water system (DWS) therefore play an important role in the general health and performance of broiler chickens [42] and consequently also in human health [59].

Bacteria attaching to the inside of DWSs and forming biofilms are the main source of drinking water contaminations [57]. Not only pathogens such as Salmonella spp. are capable of forming biofilms on the materials of the poultry DWS (i.e. plastic [60, 73];), but also commensal species such as Aeromonas spp., E. coli, Pseudomonas spp., and Sphingomonas spp. were previously described as biofilm-forming organisms in DWSs ([19]; Van Eenige et al. [66]; Liu et al. [36]; Mulamattathil et al., [40]; van der Wielen and Lut, [67]. These commensal biofilms could provide a niche for the attachment and protection of pathogens $[9,63]$. However, as bacterial inter-species interactions are mainly competitive [43], it is more likely that the presence of these commensal microorganisms prevent pathogens from attaching and/or forming a biofilm via competitive exclusion [44].

Commensal microorganisms might therefore be applied to control the presence of pathogens in the DWS. The use of living microorganisms to control other living microbes is called biocontrol. This method could be an alternative for the usually performed chemical disinfection which is not environmentally friendly and poses risks for resistance development [20]. Potential of biocontrol agents (BCAs) to reduce the number of unwanted pathogens and other organisms has already been evaluated, leading to mixed results $[8,39,72]$.

Biocontrol is based on the naturally occurring competitive interactions exerted by BCAs on the pathogen. Especially when microbial species occupy the same ecological niche, competitive interactions are expected to be dominant [22]. However, microbes can also engage in other types of social interactions [43]. In a more limited number of cases, microbial species were found to cooperate, enhancing each other's fitness [51, 52]. This potential for both positive and negative interactions between microbes raises the need for in depth characterization of the sociobiology of candidate BCAs. The cooperation criterion can be used to distinguish between cooperative and competitive interactions [43], whereas the biodiversity effect (consisting of a selection effect and a complementarity effect) provides a useful logic to further characterize the level and nature of competition $[38,49]$. Since biofilm-growth capacities of microorganisms strongly depend on several factors, including growth conditions, contact surface and taxonomy [12, 19, 34, $56,70]$, assays to evaluate social interactions should be performed under lab controlled conditions that mimic the real situation as much as possible.

In previous work [41], we identified Pseudomonas putida as part of the natural dominant microbiota on several locations on the inside of the DWS in broiler houses, but it is not known as a common contaminant on chickens. Several Pseudomonas spp. have been shown to suppress plant pathogens by antibiotic production and more specifically $P$. putida is suggested as a BCA against plant diseases $[6,62]$. In the current study, we aimed to investigate whether $P$. putida strains could also serve as BCA against Salmonella on the inside of the DWS in broiler houses. We specifically focused on Salmonella enterica subsp. enterica serotype Paratyphi B variant Java (hereafter abbreviated as $S$. Java), a serotype that is emerging in Belgian broiler houses [18] and spreads and persists easily in the farm [64, 68]. The interaction between these species was investigated based on the cooperation criterion and biodiversity effect to assess if $P$. putida biofilms promote or impede the attachment and biofilm formation by $S$. Java. Hereto, an in vitro model was developed and validated to simulate biofilm formation on the inside of the DWS of broiler chickens that approaches environmental conditions as close as possible. The effect of several $P$. putida field strains was evaluated against a $S$. Java strain isolated from broiler chicken drinking water.

\section{Results}

\section{Validation of the in vitro biofilm model}

To guarantee the relevance of the obtained results, a novel in vitro biofilm model was developed that closely resembles the environmental conditions of the DWS in broiler houses. Environmental conditions were simulated by growing biofilms on coupons made out of plastic drinking water lines for broilers. Low flow conditions in the DWS were simulated by shaking at a low speed (50 rpm) and an incubation temperature of $25^{\circ} \mathrm{C}$ was chosen to mimic the average stable environmental temperature. Nutrient conditions were approached by applying a poor growth medium during biofilm formation. Finally, as specified in 'Experimental procedures: Strain selection and preparation', field strains (2 Salmonella strains; 3 Pseudomonas putida strains) previously collected from water, broiler feed and from inside surfaces of the DWS for broilers were used to simulate biofilm formation at this specific niche [41].

Before interactions between P. putida and Salmonella were investigated, mono-species biofilms were evaluated 
for the validation and implementation of the newly developed in vitro biofilm model. Biofilms were grown using a $6 \log \mathrm{CFU} / \mathrm{mL}$ inoculum suspension of $S$. Java strain $\mathrm{S} 1$ (three independent times (days) with six technical replicates per time) and a $6 \log \mathrm{CFU} / \mathrm{mL}$ inoculum suspension of $P$. putida P2 (three independent times (days) with five technical replicates per time). Only small standard deviations between replicates and no significant differences between independent times were observed for enumerations of biofilm experiments using the same strain ( $p=0.0600$ for S1 and $p=0.1738$ for P2). An additional file shows this in more detail (see Additional file 1). Yet, OD measurements after crystal violet biomass staining provided large standard deviations between replicates and significant differences between times for both strains ( $p=0.0009$ for $\mathrm{S} 1$ and $p=0.0087$ for P2). These results demonstrate the repeatability and reproducibility of the model for biofilm quantification based on CFU enumerations. Biofilm formation in the following experiments will therefore be evaluated based on bacterial counts.

\section{Influence of strain and inoculum density on mono-species} biofilm formation

The mono-species biofilm set-up was then used to study differences in biofilm-forming capacity of different Salmonella and P. putida strains isolated from broiler DWS and feed and to evaluate the influence of inoculum density on biofilm formation. This assay revealed significant differences in biofilm formation between different strains applied with the same inoculum density (Fig. 1) and between different inoculum densities of the same strain (Fig. 2). The application of $6 \log \mathrm{CFU} / \mathrm{mL}$ of $P$. putida strains P1, P2 and P3 and Salmonella strains S1 and S2 resulted in biofilms of $6.10 \pm 0.42,6.22 \pm 0.32,6.80 \pm$ $0.13,7.31 \pm 0.22$ and $6.50 \pm 0.19 \log \mathrm{CFU} / \mathrm{cm}^{2}$, respectively. The different $P$. putida strains showed a similar trend in biofilm formation as in our previous study measuring biofilm biomass by crystal violet staining [41], with P1 producing the lowest amount of biofilm and P3 the highest. As $S$. Java (S1) has a higher biofilm-forming potential and is more prevalent and persistent in broiler practice compared to Salmonella Mbandaka (S2) ([64]; M. Cargnel, personal communication, Sciensano, April $26,2019)$, S1 was selected to evaluate the influence of inoculum density on biofilm formation and to study the interactions with $P$. putida. Decreasing the inoculum density of $S$. Java S1 led to decreased biofilm formation. $S$. Java S1 applied with an inoculum density of $6 \mathrm{log}$ $\mathrm{CFU} / \mathrm{mL}$ thus provided the highest amount of biofilm of all strains based on microbial enumerations.

\section{Influence of strain on interaction and biocontrol effect}

To study the interaction between the P. putida strains and $S$. Java, dual-species biofilms were set up by simultaneously inoculating both species in a 1:1 ratio. The $\mathrm{co}$ operation criterion states that cooperation only occurs if both strains show a lower cell number in monoculture than in mixed culture. The minimal requirement for cooperation thus entails that the total number of cells in dual culture is higher than the sum of the monocultures; otherwise the interactions are competitive, neutral or accidental [43]. Figure 3 shows that all three $P$. putida strains reduced the cell number of $S$. Java $S 1$ cells in the dual-species compared to mono-species biofilms, indicating competitive interactions between both species. $P$. putida strain P2 mediated the largest reduction of $S$. Java S1. Biofilm formation by $S$. Java $S 1$ in the presence of $P$.

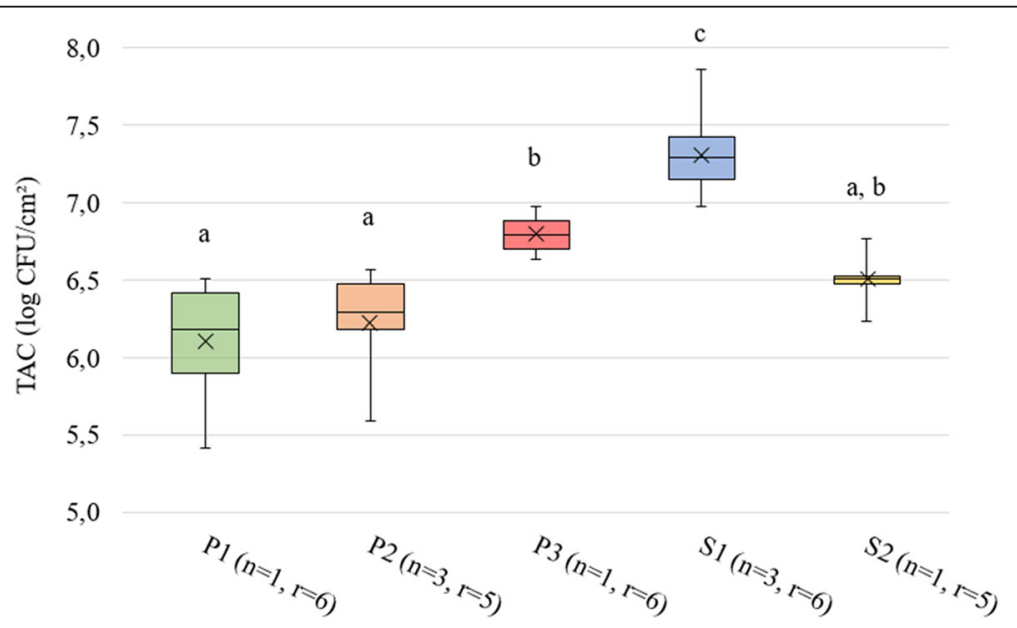

Fig. 1 Mono-species biofilm formation by different field strains. The same inoculum density ( 6 log CFU/mL) was used for attachment of the different strains followed by biofilm quantification by enumerations of total aerobic counts (TAC, $\log C F U / \mathrm{cm}^{2}$ ). Strains that did not show significantly different biofilm quantities are indicated with the same alphabetical character. $P$-values of $\leq 0.05$ were considered as significant. The number of independent tests and technical replicates per test per strain is respectively indicated by $n$ and $r$ 


\section{9,0}

a

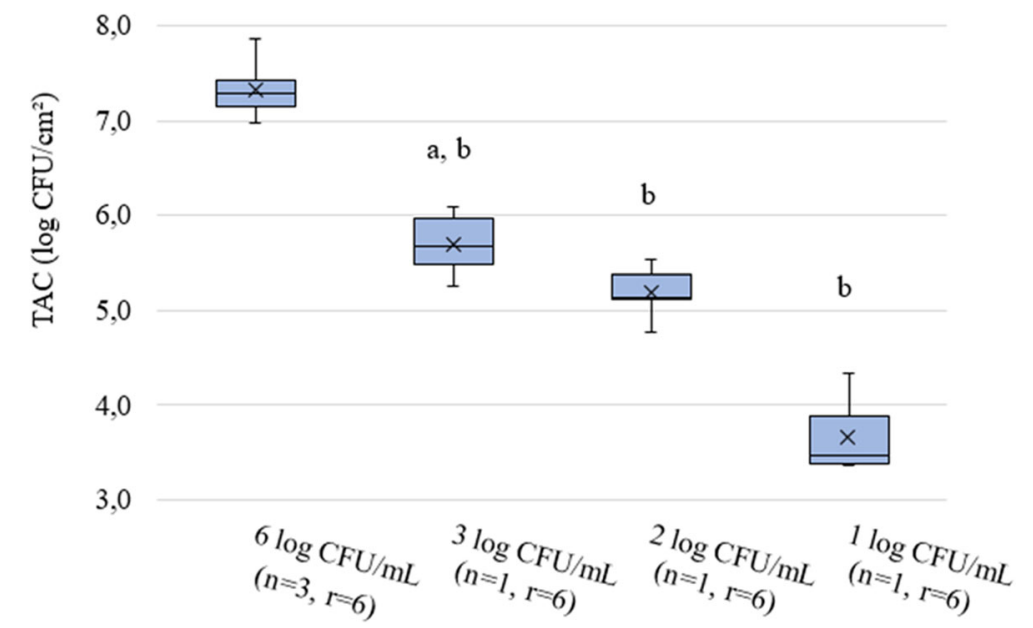

Fig. 2 Mono-species biofilm formation by S. Java strain S1. Four different inoculum densities (6, 3, 2 and $1 \log$ CFU/mL) were used for attachment followed by biofilm quantification by enumerations of total aerobic counts (TAC, log CFU/ $\mathrm{cm}^{2}$ ). Inoculum suspensions that did not provide significantly different biofilm quantities are indicated with the same alphabetical character. $P$-values of $\leq 0.05$ were considered as significant. The number of independent tests and technical replicates per test per strain is respectively indicated by $\mathrm{n}$ and $\mathrm{r}$

putida P2 was significantly lower $(p=0.0142)$ than in the presence of P1 or P3. The increase in cell number of P2 in dual-species biofilms is consistent with an exploitation of $\mathrm{S} 1$ by $\mathrm{P} 2$, resulting in dual-species biofilms with $6.31 \pm 0.23 \mathrm{P} 2$ and $6.60 \pm 0.28 \mathrm{log} \mathrm{CFU} / \mathrm{cm}^{2} \mathrm{~S} 1$. In contrast, the biofilms of other strain combinations (P1/ S1; P3/S1) are characterized by mutual inhibition, with a decrease in cell numbers of both strains in the dualcompared to mono-species conditions. This resulted in dual-species biofilms with $6.05 \pm 0.24$ and $7.03 \pm 0.17 \log$

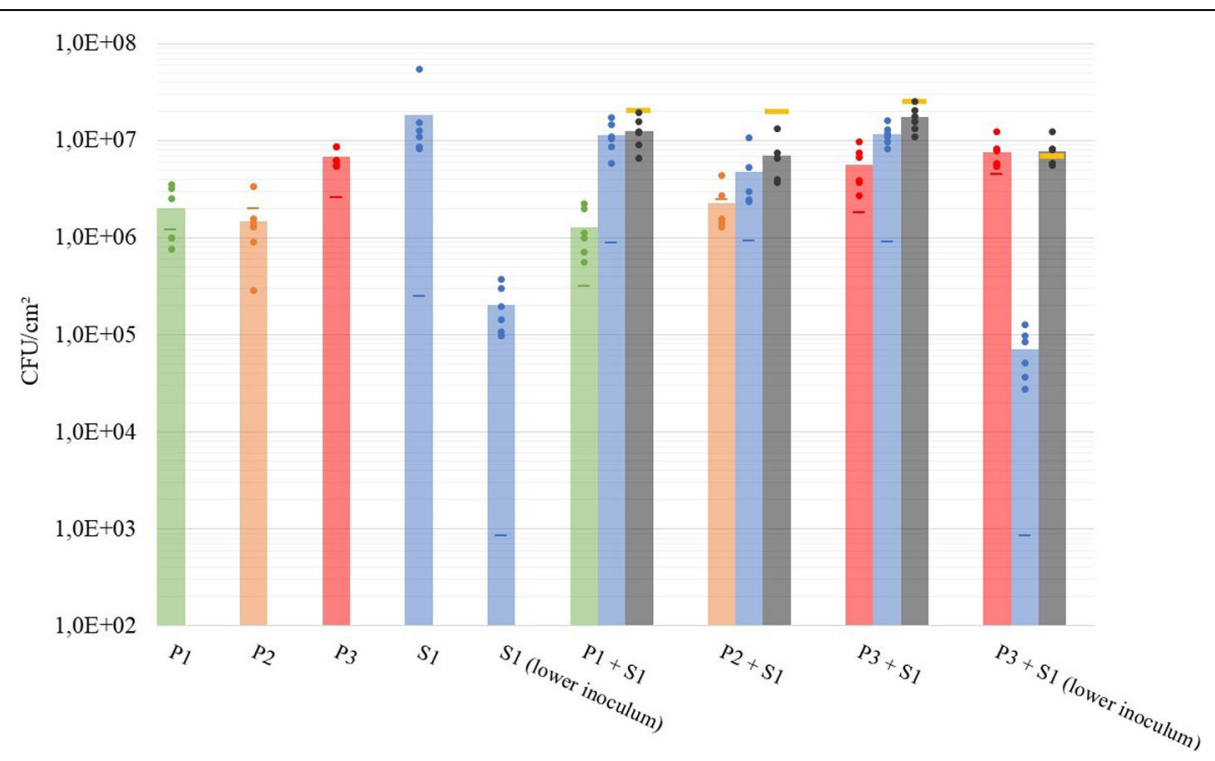

Fig. 3 Influence of strain on the interaction and biocontrol effect. Bacterial counts of each strain (P1, P2, P3 and S1) in mono-species biofilms and in dual-species biofilms are indicated. Also the influence of S1 density on its bacterial counts in dual-species biofilms was examined. The results (in CFU/ $\mathrm{cm}^{2}$ ) of six technical replicates (dots) and their average (columns) are shown per strain and in total (grey) for the dual-species biofilms. The actual inoculum density (CFU/ml) applied in every biofilm experiment is indicated with a horizontal line in the colour corresponding to the used strain. The total amount of cells expected for cooperation in dual-species biofilms is indicated as yellow horizontal lines. *Dual-species biofilms consisting of $\mathrm{P} 2+\mathrm{S} 1$ demonstrated one significant outlier, providing only five technical replicates in these results 
$\mathrm{CFU} / \mathrm{cm}^{2}$ (P1/S1) or $6.72 \pm 0.21$ and $7.05 \pm 0.10 \mathrm{log}$ $\mathrm{CFU} / \mathrm{cm}^{2}$ (P3/S1). Despite the inhibitory effect of $P$. putida, Salmonella was nevertheless still the dominant species in the dual-species biofilms when an equal amount of each strain was applied.

To further characterize the level and nature of competition we calculated the biodiversity effect [38, 49]. In case inter-species competition is equal to intra-species competition, the observed biofilm formation in dualspecies conditions is expected to be equal to the monospecies biofilm formation, weighed by the inoculum densities (expected biofilm formation). As detailed in 'Experimental procedures', the biodiversity effect is defined as the difference between the observed $\left(\mathrm{Y}_{\mathrm{O}}\right)$ and this expected $\left(\mathrm{Y}_{\mathrm{E}}\right)$ dual-species biofilm formation and is therefore a measure for the extent to which inter-species interactions differ from intra-species interactions. Dualspecies biofilms between $\mathrm{S} 1$ and P1 showed lower overall bacterial counts than expected $\left(2.31 \mathrm{E}+06 \mathrm{CFU} / \mathrm{cm}^{2}\right.$ less than expected for $\mathrm{S} 1$ and $7.47 \mathrm{E}+05 \mathrm{CFU} / \mathrm{cm}^{2}$ more than expected for P1), which is reflected in a negative biodiversity effect. On the other hand, culturing S1 together with P2 or P3 produced higher cell counts than expected as indicated by a positive biodiversity effect (Fig. 4).
Indeed, in the P2/S1 biofilms, observed biofilm formation $\left(\mathrm{Y}_{\mathrm{O}}\right)$ was higher than expected based on intraspecies competition $\left(\mathrm{Y}_{\mathrm{E}}\right)$, both for $\mathrm{S} 1$ and $\mathrm{P} 2$ (respectively $1.72 \mathrm{E}+06$ and $1.03 \mathrm{E}+06 \mathrm{CFU} / \mathrm{cm}^{2}$ ). In the $\mathrm{P} 3 / \mathrm{S} 1$ biofilms there was also an increase (observed vs. expected) in biofilm formation for both S1 $(5.42 \mathrm{E}+06$ $\left.\mathrm{CFU} / \mathrm{cm}^{2}\right)$ and $\mathrm{P} 3\left(1.18 \mathrm{E}+06 \mathrm{CFU} / \mathrm{cm}^{2}\right)$. In conclusion, P1/S1 biofilm formation appears to be lower than expected based on intra-species competition, whereas the opposite is the case for the P2/S1 and P3/S1 biofilms.

Since the biodiversity effect is the sum of the complementarity effect and the selection effect, both components were also analysed separately (Fig. 4). The negative biodiversity effect in dual-species biofilms of P1/S1 can be subdivided into a positive complementarity effect of $2.46 \mathrm{E}+06$ and a negative selection effect of $-4.02 \mathrm{E}+06$. In contrast, the complementarity and selection effect for $\mathrm{P} 2 / \mathrm{S} 1$ biofilms were calculated as $4.87 \mathrm{E}+06$ and$2.12 \mathrm{E}+06$, summing up to a positive biodiversity effect. For P3/S1 biofilms, the complementarity and selection effect were both positive $(5.91 \mathrm{E}+06$ and $6.98 \mathrm{E}+05$ respectively). The positive complementarity effect in all three communities signifies that the intra-species competition among the bacteria of the same species is

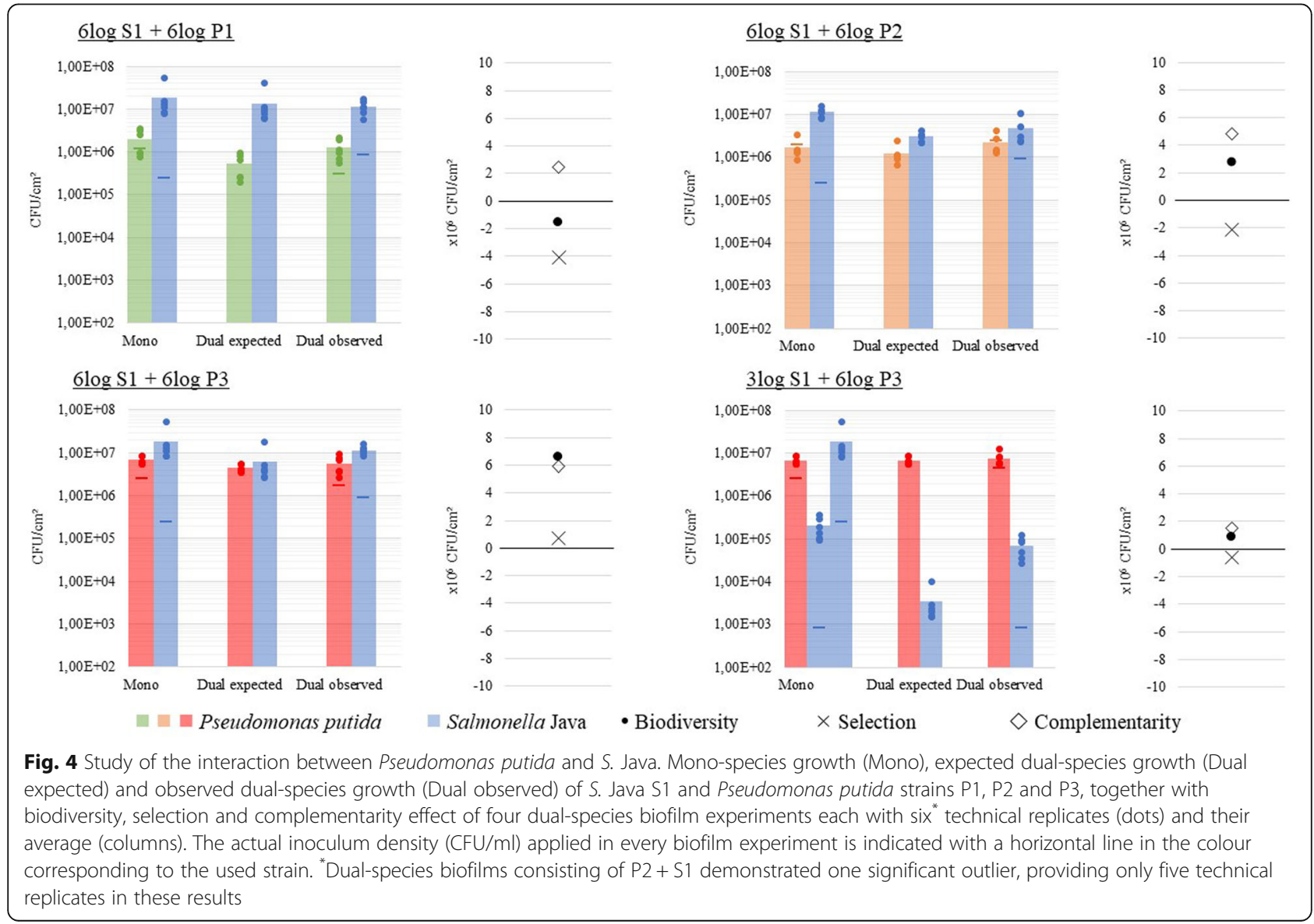


stronger than the inter-species competition between the different species. These results indicate that none of the three $P$. putida strains shows a complete overlap with $S$. Java in use of nutrients and space. Both species appear to populate partially separated ecological niches, relaxing the competition between them.

The positive selection effect in the P3/S1 biofilms indicates that S1, which is the best biofilm former in monoculture, shows the highest increase in relative biofilm formation in the dual culture biofilm compared to expected $\left(R Y_{O}-R Y_{E}\right.$ is 0.29 for $\mathrm{S} 1$ vs. 0.17 for P3). The negative selection effect in P1/S1 and P2/S1 biofilms on the contrary indicates that in these populations P. putida $\mathrm{P} 1$ and $\mathrm{P} 2$, which are worse biofilm formers in monoculture than S1, show the highest increase in relative biofilm formation (P1/ S1: $R Y_{O}-\mathrm{RY}_{\mathrm{E}}$ is -0.13 for S1 vs. 0.37 for P1; P2/S1: $\mathrm{RY}$ - $\mathrm{RY}_{\mathrm{E}}$ is 0.15 for S1 vs. 0.60 for P2) [38, 49]. However, as in absolute terms P1 and P2 make still significant less biofilm in the dual culture than S1, this 'ecological selection effect' does not translate into evolutionary selection.

\section{Influence of pathogen inoculum density on interaction and biocontrol effect}

Although Salmonella was inhibited by all three P. putida strains, it still dominated the dual-species biofilms if equal amounts of each species were applied. We therefore studied the influence of the pathogen's inoculum density on the interaction with $P$. putida by lowering the inoculum density of S1 from $6 \log \mathrm{CFU} / \mathrm{mL}$ to a more realistic $3 \log \mathrm{CFU} / \mathrm{mL}$ [5]. P. putida P3 was selected for this study because of its high mono- and dual culture level of biofilm formation, as high cell numbers and enhanced biofilm formation offer advantages in terms of persistence [7, 58, 69]. In case of this lower inoculum, Salmonella S1 was repressed by P3 to a higher proportional extent than observed for the higher inoculum (Fig. 3). Interestingly, lowering the inoculum density of S1, changed the mutually competitive interaction (at 6 $\log \mathrm{CFU} / \mathrm{mL}$ inoculum) into an exploitative interaction (at $3 \log \mathrm{CFU} / \mathrm{mL}$ inoculum), with slightly increased cell number of $P$. putida in dual-species compared to monospecies biofilms. This resulted in dual-species biofilms dominated by $P$. putida, with $6.86 \pm 0.14 \log \mathrm{CFU} / \mathrm{cm}^{2}$ of P3 and $4.79 \pm 0.26 \log \mathrm{CFU} / \mathrm{cm}^{2}$ of S1. The relative biofilm formation of both strains was again higher than expected (with 0.0037 for S1 and 0.11 for P3). The interaction was thus also still characterized by a positive complementarity effect $(1.49 \mathrm{E}+06)$, pointing towards niche separation. However the selection effect turned negative $(-6.45 \mathrm{E}+05)$, indicating that the strongest increase in relative biofilm formation was made by $\mathrm{P} 3$, which is the worst biofilm former in monoculture (Fig. 4). The negative selection effect could not completely compensate for the positive complementary, leading to an overall positive biodiversity effect.

\section{Influence of sequential application of BCA and pathogen on interaction and biocontrol effect}

Biocontrol agents have potential to be applied in a preventive manner. We therefore finally studied the effect of sequential application of P. putida P3 and S. Java S1. The potential BCA strain P3 was first allowed to attach for $4 \mathrm{~h}$ and form a biofilm for $18 \mathrm{~h}$, resulting in biofilms of $6.73 \pm 0.13 \log \mathrm{CFU} / \mathrm{cm}^{2}$. Then, an inoculum density of $3 \log \mathrm{CFU} / \mathrm{mL} \mathrm{S1}$ was applied for attachment $(4 \mathrm{~h})$ and biofilm formation $(18 \mathrm{~h})$ on the pre-existing P3 biofilm. This resulted in dual-species biofilms dominated by P. putida, with $6.89 \pm 0.11 \log \mathrm{CFU} / \mathrm{cm}^{2} \mathrm{P} 3$ and $4.98 \pm$ $0.17 \log \mathrm{CFU} / \mathrm{cm}^{2} \mathrm{~S} 1$ (Fig. 5). Absolute cell numbers of $\mathrm{S} 1$ in the resulting dual-species biofilms were lower than in mono-species $\mathrm{S} 1$ biofilms of $22 \mathrm{~h}$ old. $S$. Java biofilm formation on a pre-existing $P$. putida biofilm was thus significantly lower $(p=0.0039)$ than on clean surfaces. Also, the presence of a pre-existing biofilm of P3 could reduce the cell number of $\mathrm{S} 1$ (applied at $3 \log \mathrm{CFU} / \mathrm{mL}$ ) to a higher extent than when the strains were applied simultaneously, altough this further decrease in Salmonella level was not significant $(p=0.14)$. For P3, absolute cell numbers observed after $44 \mathrm{~h}$ of biofilm formation were higher in dual- compared to mono-species biofilms of $44 \mathrm{~h}$. When only the growth during the last $22 \mathrm{~h}$ of the experiment is considered, absolute cell numbers for P3 also increased in dual- compared to mono-species biofilms. These results thus indicate that exploitative competition is also present between $\mathrm{P} 3$ and $\mathrm{S} 1$ in the sequential set-up. The biodiversity effect in this sequential biofilm experiment was then studied based on the last $22 \mathrm{~h}$ of incubation as a reference period, i.e. when both strains were present. The cell number of P3 in the preexisting $22 \mathrm{~h}$ old biofilm was used to determine the P3 inoculum proportion $\left(\mathrm{RY}_{\mathrm{E}, \mathrm{P} 3}\right)$ in the biodiversity effect calculations. Both strains performed better than expected in the sequential set-up, with an increase in relative biofilm formation of 0.0054 for S1 and 0.76 for P3. Similarly to the simultaneous inoculation, the complementarity effect was positive $(7.94 \mathrm{E}+06)$, pointing at niche separation, and the selection effect negative ($6.02 \mathrm{E}+06)$, consistent with the highest increase in relative biofilm formation being made by the worst biofilm former in monoculture, which is P3. The negative selection effect could not compensate for the degree of complementarity, leading to an overall positive biodiversity effect (Fig. 5).

\section{Discussion}

In recent years, biocontrol as an alternative for chemical disinfection has gained strong interest. Studies have 

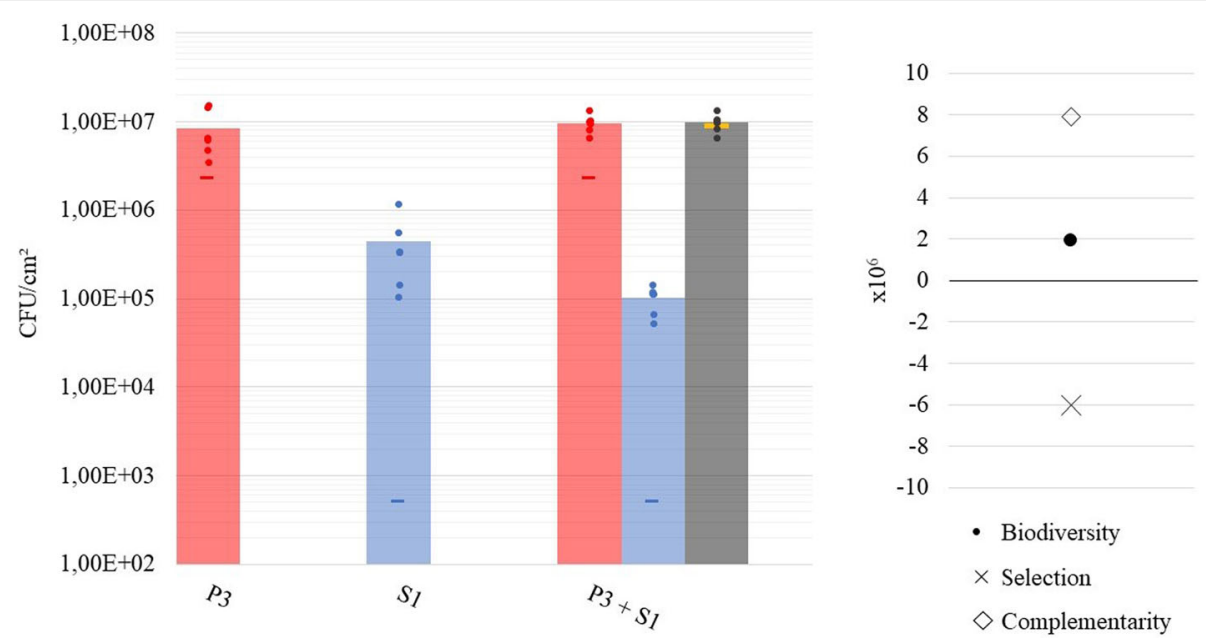

Fig. 5 Influence of sequential application of biocontrol agent and pathogen on interaction and biocontrol effect. Cell number of strains P3 and $\mathrm{S} 1$ in mono-species biofilms and in dual-species biofilms are indicated. Results (in $\mathrm{CFU} / \mathrm{cm}^{2}$ ) of the six technical replicates (dots) and their average (columns) are shown per strain and in total (grey) for the dual-species biofilms after $44 \mathrm{~h}$ of incubation, whereby $\mathrm{S1}$ was only applied during the last $22 \mathrm{~h}$. The actual inoculum density (CFU/ml) applied in every biofilm experiment is indicated with a horizontal line in the colour corresponding to the used strain. The total amount of cells expected for cooperation in dual-species biofilms is indicated as a yellow horizontal line. Also biodiversity, selection and complementarity effect, calculated based on the last $22 \mathrm{~h}$ of incubation i.e. when both strains were present, are shown

already been performed in primary animal and plant production, food industry and even in hospitals $[8,28$, $39,65,72,74]$. However, the possibility to use biocontrol agents against persistent pathogenic strains in the broiler environment has received only limited attention [2]. In this research, a realistic in vitro model for biofilm formation on the inside of the DWS was developed and validated. This model was utilized to study interactions between Salmonella Java and Pseudomonas putida strains previously isolated from DWS and to evaluate the potential of P. putida as BCA in this niche. Biofilm formation was evaluated based on bacterial counts. This quantification method proved more repeatable and reproducible compared to OD measurement of crystal violet after resolubilization. The high variation of the OD measurements for biofilm quantification was possibly due to the rinsing step under running tap water to remove the excess stain. During this step, an uncontrollable mechanic force is applied to the coupons whereby pieces of the biofilm can detach. Therefore, further optimisation is required to use OD measurement as a method to quantify biofilm formation in the newly developed in vitro biofilm model. However, bacterial counts are more valuable than OD measurements for mixed cultures as it allows to quantify the strains separately and determine the underlying social interactions. The developed model could be further expanded by incorporating a continuous flow. However, this approach would likely limit the throughput of the system.

The difference in monoculture biofilm-forming capacity between the three P. putida strains in the DWS in vitro model confirmed the previous observations concerning biofilm formation by these strains in 96-well MTPs [41]. Differences in biofilm-forming capacity between strains of the same species are commonly reported and can be due to mutations in biofilm regulating genes $[1,4,12,34,37]$. Very few literature was found concerning monoculture biofilm-forming capacity of $S$. Java. Agarwal et al. [1] screened a multitude of Salmonella serotypes, among which one $S$. Java strain, for biofilm formation in 96-well MTPs. The $S$. Java strain was evaluated as a weak biofilm former based on OD measurements. In the current study, where biofilm formation was evaluated under more realistic conditions, the $S$. Java field strain was evaluated as the best biofilm former based on bacterial counts compared to the other strains that were included (among which another Salmonella serotype i.e. Salmonella Mbandaka). Even at low inoculum densities, which are more realistic for the investigated niche [5], S. Java was capable to form a significant amount of biofilm. It was already demonstrated for Listeria monocytogenes that persistent strains show increased biofilm formation relative to nonpersistent strains $[7,58,69]$. The strong biofilm-forming capacity of the $S$. Java strain in this study could therefore be an explanation for the persistent character of this Salmonella serotype in broiler houses. A framework based on the cooperation criterion [43] and biodiversity effect (consisting of a selection effect and a complementarity effect) $[38,49]$ was applied to characterize the social interactions between $S$. Java and the three $P$. putida strains. The study of social interaction provides essential 
information to identify effective BCAs. Several characteristics should be taken into account. First, it is advantageous if the BCA shows a strong inhibitory effect and a high cell number when co-cultured with the strain to be controlled. If the BCA has a higher number of cells than the unwanted strain this would indicate the BCA has a higher fitness in this niche, leading to gradual enrichment (selection) and higher dominance of the BCA over time. Furthermore, the niche overlap between the BCA and the unwanted strain should be maximal, preferentially leading to high levels of interference competition. Both factors are reflected in a low (preferentially negative) complementarity effect.

All evaluated $P$. putida strains were able to some extent to reduce the attachment and biofilm formation by $S$. Java, supporting the potential of P. putida as a BCA against $S$. Java in the DWS of broiler houses. The ability of Pseudomonas strains to inhibit the growth of several pathogenic bacteria, among which Salmonella, was previously attributed to the production of iron-capturing siderophores and the toxic pigment pyocyanin [11, 17, $24,29,45]$. P. putida specifically also produces several biosurfactants that can inhibit biofilm formation and even break down existing biofilms [31]. In addition, in silico genome mining revealed two clusters for biosynthesis of bacteriocins and one cluster for a type I polyketide synthase. $P$. putida thus has a wide arsenal of weaponry that could inhibit $S$. Java biofilm formation. The positive complementarity in the co-cultures does not point towards strong interference competition among $S$. Java and $P$. putida. However, a positive complementarity does not exclude that interference competition takes place as it is possible that the inhibitory effect of interference competition is compensated by the benefits of niche separation, resulting in a net positive complementarity.

All three $P$. putida strains showed different inhibitory effects on $S$. Java. When inoculated in equal amounts, strain P2 inhibited $S$. Java to the highest extent and even increased its own biofilm formation compared to monoculture. The other $P$. putida strains also inhibited $S$. Java significantly, albeit to a lower extent, and they formed less biofilm in mixed- than in mono-culture. The observation that all three $P$. putida strains engage in competitive interactions with $S$. Java fits with a growing body of recent theoretical and experimental work indicating that competition, not cooperation, dominates interactions among microbial species [22, 43, 49]. More specifically, interactions between Pseudomonas aeruginosa and Salmonella Enteritidis and Typhimurium, between Pseudomonas fluorescens and Salmonella Typhimurium, Montevideo and Poona, and between P. putida and Salmonella enterica were also identified as competitive ([13, 33, 46-48]). In general, interactions between Pseudomonas and other
Enterobacteriaceae such as Escherichia coli and Klebsiella pneumoniae are also predominantly competitive, however the species dominating the co-culture and whether mutual inhibition or exploitation occurs is strongly strain- and condition-dependent $([10,15,23,35,71)$. Moreover, the type of interaction between strains is greatly dependent on environmental conditions, among which the stress gradient plays an important role [51]. Therefore, the presence of medication administered through the DWS can also influence the interaction between $P$. putida and $S$. Java in practice.

Although all interactions were competitive in nature, the positive complementarity effects in all strain combinations indicate that the niches between both species do not completely overlap, alleviating the competitive interactions. In addition, despite the inhibitory effect of $P$. putida, Salmonella remained the dominant species when equal inoculum densities were applied as counts for Salmonella were always higher than counts for Pseudomonas spp. The dominance of Salmonella Typhimurium relative to Pseudomonas aeruginosa in dual-species biofilms was already described by Pang et al. [47], but in the same study Salmonella Enteritidis was equally distributed to $P$. aeruginosa. In contrast to our study, coexistence between Pseudomonas and Salmonella Agona enhanced biofilm formation by $S$. Agona in terms of increased biovolume in the study of Habimana et al. [25]. Overall, this suggests that the behaviour of Salmonella in dual-species biofilms with Pseudomonas is strongly dependent on respectively serotype and strain. In addition, differences in biofilm growth conditions (flow, incubation time, incubation temperature, stress factors, surface type, etc.) could also lead to different interactions between the strains $[16,51]$.

Consistently, we found that changing the inoculum ratio affects the outcome of competition greatly. When the inoculum proportion of $\mathrm{P} 3 / \mathrm{S} 1$ was lowered to a more realistic 1:0.001, P3 was able to exploit resources provided by competitor $S$. Java and dominate the biofilm. This exploitation could for example be due to superior positioning in the biofilm or the consumption of metabolic by-products generated by Salmonella [30, 49, 50, 55]. When P. putida was first allowed to form a biofilm on the surface of the DWS and only afterwards $S$. Java was applied, a further increase in the competitive effect against $S$. Java was established, as evident by a stronger percentage reduction in Salmonella cell numbers. Again, P. putida was able to dominate the biofilm and exploit $S$. Java. One possible explanation for the enhanced inhibitory effect in the sequential set-up is that $P$. putida covers the abiotic surface and prevents the adhesion of Salmonella in a process called surface blanketing [53]. However, surface blanketing is unlikely, due to the low density of the $P$. putida biofilms. Indeed, prior research indicates that at similar densities 
Pseudomonas forms a sparse biofilm that does not cover the complete surface [21]. The above described effects of nutrient and interference competition are therefore likely more important.

Although $S$. Java was inhibited by the $P$. putida strains, prevention of Salmonella colonization was far from complete. Moreover, it is not known which impact this reduction in $S$. Java biofilm formation will have on the prevalence of $S$. java in broilers or on broiler meat. Given the strain variations observed in this study, other $P$. putida strains might be able to reduce $S$. Java to an even higher extent. It would therefore be interesting to evaluate the biocontrol potential of additional P. putida strains, possibly in combination with other Salmonellabiocontrol species. Moreover, biofilms on the inside of the DWS in broiler houses are composed of a diverse range of microorganisms [41], which might also interact with pathogen and BCA. Future biocontrol assays should take this species diversity into account.

Another important factor to consider is that, although co-culturing Salmonella and Pseudomonas can lead to less biofilm formation by Salmonella, different studies reported an increased Salmonella tolerance to disinfectants in these mixed species biofilms [33, 48]. Parijs and Steenackers [49] reported this increased tolerance can be a consequence of competitive release in the biofilm upon treatment or of an increase in inherent tolerance due to the presence of competing species. Another downside of biofilms present on the inside of the DWS in broiler houses (independent on the strain composition) is clogging of the pipes and capture of medicine particles, leading to under dosing of the animals and increasing the risk for animal health and the development of drug resistant strains [27, 54]. Therefore also the combination of biocontrol strategies and chemical (disinfection/drug) treatments should be investigated.

\section{Conclusions}

In conclusion, the present study indicates the potential of P. putida as a biocontrol agent against $S$. Java. Competitive interactions were observed between both genera in a newly developed and validated in vitro model that simulates biofilm formation on the inside of the DWS in broiler houses under realistic conditions. When equal inocula were simultaneously applied, the interaction between $S$. Java and $P$. putida strains P1 and P3 was characterized as mutually inhibitory, whereas $P$. putida strain P2 showed an exploitation of $S$. Java. Lowering the inoculum density of $S$. Java changed the mutually competitive interaction with $P$. putida strain P3 also into an exploitation by P3 and enhanced the competitive inhibition of $S$. Java. A further increase in $S$. Java inhibition was established by allowing $P$. putida (strain P3) to form a mature biofilm before applying $S$. Java. Future studies should extend this work by including more complex resident microbial communities from the DWS niche, additional Salmonella strains and other zoonotic pathogens frequently occurring in the broiler industry (such as Campylobacter spp.), as well as chemicals typically applied to clean and disinfect the systems.

\section{Methods \\ Strain selection and preparation}

To study the potential of Pseudomonas putida as BCA against Salmonella, several field strains from broiler houses were used (Table 1). The P. putida strains were in a previous study [41] classified as weak (P1), moderate (P2) and strong (P3) biofilm formers in 96-well microtiter plates (MTPs). This classification was based on the absorbance measured at $590 \mathrm{~nm}$ after crystal violet staining of the biofilms, which was divided into groups according to Stepanović et al. [61].

For the preparation of the bacterial suspension for inoculation in the in vitro biofilm model, strains were streaked on Plate Count Agar (PCA, Oxoid, CM0325, Basingstoke, Hampshire, England) from their glycerol stocks at $-80^{\circ} \mathrm{C}$ and incubated for $24 \mathrm{~h}$ at $37^{\circ} \mathrm{C}$ for Salmonella strains and $48 \mathrm{~h}$ at $30^{\circ} \mathrm{C}$ for Pseudomonas strains. Subsequently, one colony from PCA was transferred to a test tube containing $10 \mathrm{~mL}$ of Tryptone Soya Broth (TSB, Oxoid, CM0129). An overnight culture was obtained by incubating the broth for $18 \mathrm{~h}$ at $30^{\circ} \mathrm{C}$ for Pseudomonas ( $8 \log \mathrm{CFU} / \mathrm{mL}$ ) or $18 \mathrm{~h}$ at $37^{\circ} \mathrm{C}$ for Salmonella (9 log CFU/mL) strains. Quantification of the overnight culture was done by plating on PCA and incubation for $72 \mathrm{~h}$ at 30 or $37^{\circ} \mathrm{C}$ depending on the species. Finally, overnight cultures were diluted in sterile $1 / 4$ Ringer's solution (Biokar, BR00108, Beauvais, France) to the desired density (3 or $6 \log \mathrm{CFU} / \mathrm{mL}$ depending on the corresponding biofilm set-up) and the resulting suspension is called the inoculum suspension. Actual inoculum densities were calculated based on the CFU quantification of the overnight cultures and were taken into account in the study of the interactions between strains in dual-species biofilms.

\section{Model preparation}

Coupons, 35x10x2mm, were cut from new plastic drinking water lines commonly used in broiler houses (Swii'Flo, Roxell, Maldegem, Belgium). Before use, these coupons were sterilized in $70 \%$ ethanol for $10 \mathrm{~min}$ and dried in a laminar flow cabinet. The sterilized coupons were vertically placed in the wells of a 6-well MTP (Novolab, SPL30006, Geraardsbergen, Belgium) using sterilized tweezers in a way that only the $2 \mathrm{~mm}$ sides of the coupons touch the wells. 
Table 1 Field strains to study the potential of Pseudomonas putida as BCA against Salmonella Java

\begin{tabular}{|c|c|c|c|}
\hline Strain & Identity & Abbreviations & Origin \\
\hline KS243 & $\begin{array}{l}\text { Salmonella enterica subsp. enterica serovar Paratyphi B } \\
\text { variant Java }\end{array}$ & $\begin{array}{l}\text { Salmonella Java, S. Java, } \\
\text { S1 }\end{array}$ & $\begin{array}{l}\text { Drinking water of broiler chickens on Belgian broiler } \\
\text { farm }\end{array}$ \\
\hline MB1560 & Salmonella enterica subsp. enterica serotype Mbandaka & $\begin{array}{l}\text { Salmonella Mbandaka, } \\
\text { S2 }\end{array}$ & Broiler feed \\
\hline MB6188 & Pseudomonas putida & P1 & Inside surfaces of the DWS in broiler houses \\
\hline MB6189 & Pseudomonas putida & P2 & Inside surfaces of the DWS in broiler houses \\
\hline MB6275 & Pseudomonas putida & P3 & Inside surfaces of the DWS in broiler houses \\
\hline
\end{tabular}

\section{Mono- and dual-species biofilm formation Attachment of the bacterial strains}

For each independent test (n) of each tested strain (combination) and condition, a 6-well MTP was used for biofilm formation. In this plate, $11 \mathrm{~mL}$ of inoculum suspension was added per well (technical replicates $=r$ ) to completely submerge the coupons. A second 6-well MTP was used as blank control. In this plate, $11 \mathrm{~mL}$ of diluted TSB (equally diluted as the inoculum suspension) was applied in three wells. Only for the validation of the model, a third MTP was used for biofilm formation. Well plates were incubated in an incubator with shaker (Adolf Kuhner ag, LT-V 89799.89, Basel, Switzerland) for $4 \mathrm{~h}$ at $25^{\circ} \mathrm{C}$ and $50 \mathrm{rpm}$ making attachment of the bacteria to the coupons possible. After incubation, coupons were removed from the 6-well MTPs and transferred to $15 \mathrm{~mL}$ falcon tubes (Sigma-Aldrich, Z720461-50EA, Overijse, Belgium) using sterilized tweezers. To remove nonattached bacteria, coupons were rinsed once by submerging them in $10 \mathrm{~mL}$ sterile $1 / 4$ Ringer's solution in the falcon tubes. Afterwards, the $1 / 4$ Ringer's suspension was discarded and coupons with attached bacteria were placed vertically in new 6-well MTPs.

\section{Biofilm formation by the attached bacterial strains}

The new MTP's with coupons were filled with $11 \mathrm{~mL}$ of sterile $1 / 20$ diluted TSB per well and subsequently incubated for $18 \mathrm{~h}$ at $25^{\circ} \mathrm{C}$ and $50 \mathrm{rpm}$ to allow the attached bacteria to form biofilm. After incubation, coupons were removed from the 6-well MTPs and transferred to 15 $\mathrm{mL}$ falcon tubes using sterilized tweezers. To remove non-attached bacteria, coupons were rinsed three times by consecutively adding $10 \mathrm{~mL}$ of sterile $1 / 4$ Ringer's solution in the falcon tubes and discarding the suspension. Finally, coupons were transferred to new sterile $15 \mathrm{~mL}$ falcon tubes.

\section{Quantification of biofilm formation based on bacterial counts}

Coupons originating from the first MTP were used for quantification of biofilm formation by conventional microbial enumeration methods. Three blank control coupons from the second MTP were also counted to ensure no contamination did occur during analysis. First, $10 \mathrm{~mL}$ of sterile $1 / 4$ Ringer's solution was added to the falcon tubes containing the coupons. Then, three consecutive rounds of sonication for $30 \mathrm{~s}$ at $42 \mathrm{kHz}$ in a ultrasonic water bath (Branson, 2510, Eemnes, The Netherlands) and vortexing for $30 \mathrm{~s}$ were performed to harvest the biofilm.

The liquid suspension containing the detached biofilm cells was plated on Tryptone Soya Agar (TSA, Oxoid, CM0131) for enumerations of total aerobic count (TAC) and a second, more selective, medium. This selective medium was Xylose Lysine Desoxycholate Agar (XLD, Oxoid, CM0469) for Salmonella and Pseudomonas Agar Base (PAB; Oxoid, CM0559) with Pseudomonas CFC Selective Agar Supplement (Oxoid, SR0103) for Pseudomonas. Appropriate 10-fold dilutions were made in sterile $0,1 \% \mathrm{w} / \mathrm{v}$ Peptone Water with $0,85 \% \mathrm{w} / \mathrm{v}$ Salt (BioTrading, K110B009AA, Mijdrecht, The Netherlands) and pour plated. TSA plates were incubated for $72 \mathrm{~h}$ at $30^{\circ} \mathrm{C}$ or $37^{\circ} \mathrm{C}$ for Pseudomonas or Salmonella biofilms, respectively. XLD plates were incubated for $72 \mathrm{~h}$ at $37^{\circ} \mathrm{C}$ and $P A B$ plates were incubated for $72 \mathrm{~h}$ at $30^{\circ} \mathrm{C}$. The limit of quantification (LOQ) for microbiological enumerations was $1,16 \log \mathrm{CFU} / \mathrm{cm}^{2}$.

\section{Quantification of biofilm formation based on biomass}

For the validation of the model, six coupons from the third MTP used for biofilm formation and three blank control coupons from the second MTP were used for quantification of biofilm formation based on biomass. $10 \mathrm{~mL}$ of a $0.1 \%$ crystal violet solution (containing $0.1 \mathrm{~g} /$ $100 \mathrm{~mL}$ crystal violet (Merck, 101,418, Darmstadt, Germany) dissolved in one part of methanol (Biosolve, 13,687,802, CE Valkenswaard, The Netherlands), one part of isopropanol (Merck, 1.09634) and 18 parts of Phosphate Buffered Saline (Oxoid, BR0014G)) was added to each of the falcon tubes for $20 \mathrm{~min}$ and shaken (Fisher Bioblock Scientific, KL2 6118 CU 00246, Merelbeke, Belgium) at $350 \mathrm{rpm}$ for the staining of the total biomass of the biofilm on the coupons. The excess stain was removed by placing the tubes under gently running tap water. Retained crystal violet was dissolved by adding 10 $\mathrm{mL}$ of $33 \%$ acetic acid (Merck, 1.00063) for $15 \mathrm{~min}$ at 
350rmp. The absorbance was measured at $590 \mathrm{~nm}$ using a spectrophotometer (Jasco, V-660, Pfungstadt, Germany). OD-measurements of the blank control coupons were subtracted from the OD-measurements of the biofilm coupons.

\section{Study of interactions between bacterial strains in dual- species biofilms}

In this study, the cooperation criterion and the biodiversity effect were calculated to determine social interactions between $S$. Java and P. putida and to consequently assess the potential of $P$. putida as BCA. The cooperation criterion requires that the inoculation density in co-culture equals the sum of inoculation densities of the monocultures whereas the biodiversity effect imposes that the inoculation density of each species in co-culture should be its inoculation density in monoculture divided by the number of species in co-culture [49]. A preliminary experiment was conducted growing mono-species biofilms of $S$. Java in both set-ups but no differences in final biofilm growth were observed. Therefore, both the cooperation criterion and the biodiversity effect were calculated based on the results of dual-species biofilms where the inoculation density equals the sum of the inoculation densities of the monocultures.

Concerning the cooperation criterion, counts for TAC of the dual culture were compared with the sum of the counts for TAC of the two monocultures of Salmonella and Pseudomonas. Also, counts for Salmonella spp. on XLD and Pseudomonas spp. on PAB were compared between mono and dual cultures.

The biodiversity effect can be calculated as follows [38]:

$$
\Delta Y=Y_{O}-Y_{E}=N \Delta \bar{R} Y \bar{M}+N \operatorname{cov}(\Delta R Y, M)
$$

$\mathrm{N}=$ number of species in mixed-species community.

$M_{i}=$ growth of species i in mono-species conditions.

$R Y_{E, i}=$ expected relative biofilm growth of species $\mathrm{i}$ in mixed-species conditions, which is its proportion inoculated.

$R Y_{O, i}=Y_{O, i} / M_{i}=$ observed relative growth of species $\mathrm{i}$ in mixed-species.

$\Delta R Y_{i}=R Y_{O, i}-R Y_{E, i}=$ deviation from expected relative growth of species $\mathrm{i}$ in mixed-species conditions.

This biodiversity effect measures how inter-species interactions differ from intra-species interactions based on the difference between the observed multispecies biofilm productivity and an expected value derived from the productivity in mono-species biofilms. The biodiversity effect is the sum of the selection effect $(N \operatorname{cov}(\triangle R Y, M))$ and the complementarity effect ( $N \Delta \bar{R} Y \bar{M})$. The selection effect comprises deviations from the expected productivity due to relative enrichment of strong biofilm or weak biofilm formers. A positive selection effect indicates enrichment of the strongest monoculture biofilm formers, whereas a negative selection indicates that the weaker biofilm producers are enriched. The complementarity effect measures to what extent deviations from the expected relative productivity are compensated by the other strains. It comprises all deviations from the expected productivity not explained by the selection effect. A positive complementary indicates some degree of niche separation between the different strains whereas a negative complementary points towards interference competition. Interpretation of these effects is further explained in the results and discussion section.

\section{Statistical analysis}

Statistical analyses on the obtained microbiological and biomass results were carried out using Statistical Analysis System software $\left(\mathrm{SAS}^{\oplus}\right.$, version 9.4, SAS Institute Inc., Cary, NC, USA). First, normal distribution of the OD measurements and of the log transformed enumerations per microbiological parameter per biofilm experiment were evaluated based on the histogram and QQ plot. For the evaluation of the reproducibility of the model system, a Kruskal Wallis test was used to compare results for OD measurement and enumerations between the three experiments per strain. For the comparison of mono-species biofilm formation of different bacterial strains, enumerations of TAC were evaluated per experiment using ANOVA. Post-hoc pairwise comparisons were made using Scheffe test. For the comparison of mono-species biofilm formation with different inoculum densities, enumerations of TAC were evaluated per experiment using a Kruskal Wallis test. Posthoc pairwise comparisons were made using Dunn test. For the comparison of the quantification of different dual-species biofilms (with different strains, different inoculum densities or different application order) again a Kruskal Wallis test was performed on enumerations of TAC, Pseudomonas spp. and Salmonella spp. followed by a post-hoc pairwise comparison using Dunn test to indicate possible differences. $P$-values $\leq 0.05$ were considered significant.

\section{Supplementary Information}

The online version contains supplementary material available at https://doi. org/10.1186/s12866-020-02046-5.

Additional file 1:. Validation of the in vitro biofilm model.

Acknowledgements

This work would not have been possible without the help of Sjarlotte Willems. Also many thanks to Ann Van De Walle, Sofie De Vlam, Eline Dumoleijn and Elly Engels for their participating assistance. 


\section{Authors' contributions}

SM performed the sampling on broiler farms, in vitro biofilm model experiments, biofilm quantification, study of microbial interactions and statistical analysis on these data. SM discussed and interpreted the results obtained in the in vitro biofilms and was the main writer of the manuscript. SWW was a major support in statistical analysis. HS and BL provided help in the interpretation of results in the study of microbial interactions. KDR, BL, $\mathrm{MH}$ and $\mathrm{HS}$ made important adjustments to the manuscript. All authors have read and approved the manuscript.

\section{Funding}

This research is funded by Flanders'Food (KILLFILM project), by Flanders Research Institute for Agriculture, Fisheries and Food (ILVO) and by the University of Leuven (KU Leuven) (CELSA/18/031 and C24/18/046). ILVO contributed to the design of the study, collection, analysis and interpretation of the data and to writing the manuscript. KU Leuven contributed to the design of the study, analysis and interpretation of the data and to writing the manuscript.

\section{Availability of data and materials}

All data generated or analysed during this study are included in this published article and its supplementary information files.

\section{Ethics approval and consent to participate}

Not applicable.

\section{Consent for publication}

Not applicable.

\section{Competing interests}

The authors declare that they have no competing interests.

\section{Author details}

${ }^{1}$ Flanders Research Institute for Agriculture, Fisheries and Food (ILVO), Technology and Food Science Unit, Brusselsesteenweg 370, 9090 Melle, Belgium. ${ }^{2}$ Faculty of Bioscience Engineering, Department of Microbial and Molecular Systems (M2S), Centre of Microbial and Plant Genetics (CMPG), University of Leuven, Kasteelpark Arenberg 20 box 2460, 3001 Leuven, Belgium. ${ }^{3}$ Faculty of Veterinary Medicine, Department of Pathology, Bacteriology and Poultry Diseases, Ghent University, Salisburylaan 133, 9820 Merelbeke, Belgium.

Received: 8 June 2020 Accepted: 19 November 2020

\section{Published online: 11 December 2020}

\section{References}

1. Agarwal RK, Singh S, Bhilegaonkar KN, Singh VP. Optimization of microtitre plate assay for the testing of biofilm formation ability in different Salmonella serotypes. Int Food Res J. 2011;18:1493-8.

2. Alves LFA, Oliveira DGP, Lambkin T, Bonini AK, Alves V, Pinto FGS, Scur MC Beauveria Bassiana applied to broiler chicken houses as biocontrol of Alphitobius Diaperinus panzer (Coleoptera: Tenebrionidae), an avian pathogens vector. Brazilian J Poult Sci. 2015;17:459-66.

3. Antunes P, Mourão J, Campos J, Peixe L. Salmonellosis: the role of poultry meat. Clin Microbiol Infect. 2016;22:110-21.

4. Arevalo-Ferro C, Reil G, Görg A, Eberl L, Riedel K. Biofilm formation of Pseudomonas putida IsoF: the role of quorum sensing as assessed by proteomics. Syst Appl Microbiol. 2005;28:87-114.

5. Berghaus RD, Thayer SG, Law BF, Mild RM, Hofacre CL, Singer RS. Enumeration of Salmonella and campylobacter spp. in environmental farm samples and processing plant carcass rinses from commercial broiler chicken flocks. Appl Environ Microbiol. 2013;79:4106-14.

6. Bernal P, Allsopp LP, Filloux A, Llamas MA. The Pseudomonas putida T6SS is a plant warden against phytopathogens. ISME J. 2017;11:972-87.

7. Borucki MK, Peppin JD, White D, Loge F, Call DR. Variation in biofilm formation among strains of Listeria monocytogenes. Appl Environ Microbiol. 2003;69:7336-42.

8. Bosmans L, De Bruijn I, Gerards S, Moerkens R, Van Looveren L, Wittemans L, et al. Potential for biocontrol of hairy root disease by a Paenibacillus clade. Front Microbiol. 2017:8:1-11.
9. Buswell CM, Herlihy YM, Lawrence LM, McGuiggan JTM, Marsh PD, Keevil CW, Leach SA. Extended survival and persistence of Campylobacter spp. in water and aquatic biofilms and their detection by immunofluorescentantibody and -rRNA staining. Appl Environ Microbiol. 1998;64:733-41.

10. Cerqueira L, Oliveira JA, Nicolau A, Azevedo NF, Vieira MJ. Biofilm formation with mixed cultures of Pseudomonas aeruginosa/Escherichia coli on silicone using artificial urine to mimic urinary catheters. Biofouling. 2013;29:829-40.

11. Cheng C-M, Doyle MP, Luchansky JB. Identification of Pseudomonas fluorescens strains isolated from raw pork and chicken that produce siderophores antagonistic towards foodborne pathogens. J Food Prot. 1995; 58:1340-4.

12. Chia TWR, Goulter RM, McMeekin T, Dykes GA, Fegan N. Attachment of different Salmonella serovars to materials commonly used in a poultry processing plant. Food Microbiol. 2009;26:853-9.

13. Chorianopoulos NG, Giaouris ED, Skandamis PN, Haroutounian SA, Nychas G-JE. Disinfectant test against monoculture and mixed-culture biofilms composed of technological, spoilage and pathogenic bacteria: bactericidal effect of essential oil and hydrosol of Satureja thymbra and comparison with standard acid-base sanitizers. J Appl Microbiol. 2008;104:1586-96.

14. Cosby DE, Cox NA, Harrison MA, Wilson JL, Buhr RJ, Fedorka-Cray PJ. Salmonella and antimicrobial resistance in broilers: A review. J Appl Poult Res. 2015;24:408-26.

15. Culotti A, Packman Al. Pseudomonas aeruginosa promotes Escherichia coli biofilm formation in nutrient-limited medium. PLoS One. 2014;9(9):e107186.

16. Dai $D$, Raskin $L, X i C$. The effect of interactions between a bacterial strain isolated from drinking water and a pathogen surrogate on biofilms formation diverged under static vs flow conditions. J Appl Microbiol. 2017;123:1614-27.

17. Das S, Das P. Effect of cultivation media components on biosurfactant and pigment production from Pseudomonas aeruginosa PAO1. Braz J Chem Eng. 2015:32:317-24.

18. Dierengezondheidszorg Vaanderen vZw. (2020). Resultaten Salmonella-analyses bij Belgisch pluimvee in 2019. Retrieved from https:/mww.dgz.be/sites/default/files/ Overzicht_resultaten_Salmonella-analyses_bij_pluimvee_in_2019.pdf.

19. Elhariry H, Gherbawy Y, El-Deeb B, Altalhi A. Molecular identification and biofilm-forming ability of culturable aquatic bacteria in microbial biofilms formed in drinking water distribution networks. Geomicrobiol J. 2012;29:561-9.

20. Fraise AP. Biocide abuse and antimicrobial resistance: a cause for concern? J Antimicrob Chemother. 2002;49:11-2.

21. Furiga A, Lajoie B, El Hage S, Baziard G, Roques C. Impairment of Pseudomonas aeruginosa biofilm Resistance to antibiotics by combining the drugs with a new quorum-sensing inhibitor. Antimicrob Agents Chemother. 2015;60(3):1676-86.

22. Ghoul M, Mitri S. The ecology and evolution of microbial competition. Trends Microbiol. 2016;24:833-45.

23. Gomes LC, Piard JC, Briandet R, Mergulhão FJ. Pseudomonas grimontii biofilm protects food contact surfaces from Escherichia coli colonization. LWT-Food Sci Technol. 2017;85:309-15.

24. Gram L. Inhibitory effect against pathogenic and spoilage bacteria of Pseudomonas strains isolated from spoiled and fresh fish. Appl Environ Microbiol. 1993;59:2197-203.

25. Habimana O, Møretrø T, Langsrud S, Vestby LK, Nesse LL, Heir E. Micro ecosystems from feed industry surfaces: A survival and biofilm study of Salmonella versus host resident flora strains. BMC Vet Res. 2010;(6):48.

26. Heyndrickx M, Vandekerchove D, Herman L, Rollier I, Grijspeerdt K, De Zutter L. Routes for Salmonella contamination of poultry meat: epidemiological study from hatchery to slaughterhouse. Epidemiol Infect. 2002;129:253-65.

27. Høiby N, Bjarnsholt T, Givskov M, Molin S, Ciofu O. Antibiotic resistance of bacterial biofilms. Int J Antimicrob Agents. 2010;35:322-32.

28. Hossain Ml, Sadekuzzaman M, Ha S-D. Probiotics as potential alternative biocontrol agents in the agriculture and food industries: a review. Food Res Int. 2017;100:63-73.

29. Khare A, Tavazoie S. Multifactorial Competition and Resistance in a TwoSpecies Bacterial System. PLoS Gen. 2015;11:e1005715.

30. Kim W, Racimo F, Schluter J, Levy SB, Foster KR. Importance of positioning for microbial evolution. Proc Natl Acad Sci. 2014;111:E1639-47.

31. Kuiper I, Lagendijk EL, Pickford R, Derrick JP, Lamers GEM, Thomas-Oates JE, Lugtenberg BJJ, Bloemberg GV. Characterization of two Pseudomonas putida lipopeptide biosurfactants, putisolvin I and II, which inhibit biofilm formation and break down existing biofilms. Mol Microbiol. 2004;51:97-113.

32. bacterial communities in unchlorinated drinking water distribution system: An integral study of bulk water, suspended solids, loose deposits, and pipe wall biofilm. Environ. Sci. Technol. 48:5467-5476. 
33. Leriche V, Carpentier B. Viable but nonculturable Salmonella typhimurium in single- and binary-species biofilms in response to chlorine treatment. J Food Prot. 1995;58:1186-91.

34. Lianou A, Koutsoumanis KP. Strain variability of the behavior of foodborne bacterial pathogens: a review. Int J Food Microbiol. 2013;167:310-21.

35. Lopes SP, Machado I, Pereira MO. Role of planktonic and sessile extracellular metabolic byproducts on Pseudomonas aeruginosa and Escherichia coli intra and interspecies relationships. J Ind Microbiol Biotechnol. 2011;38:133-40.

36. Liu G, Bakker GL, Li S, Vreeburg JHG, Verberk JQJC, Medema GJ, Liu WT, Van Dijk JC. Pyrosequencing reveals bacterial communities in unchlorinated drinking water distribution system: An integral study of bulk water, suspended solids, loose deposits, and pipe wall biofilm. Environ. Sci Technol. 2014;48:5467-76.

37. López-Sánchez A, Leal-Morales A, Jiménez-Díaz L, Platero Al, Bardallo-Pérez J, Díaz-Romero A, et al. Biofilm formation-defective mutants in Pseudomonas putida. FEMS Microbiol Lett. 2016;363:1-10.

38. Loreau M, Hector A. Partitioning selection and complementarity in biodiversity experiments. Nature. 2001;412:72-6.

39. Luyckx K, Millet S, Van Weyenberg S, Herman L, Heyndrickx M, Dewulf J, De Reu K. Comparison of competitive exclusion with classical cleaning and disinfection on bacterial load in pig nursery units. BMC Vet Res. 2016;12:1-10.

40. Mulamattathil SG, Bezuidenhout C, Mbewe M. Biofilm formation in surface and drinking water distribution systems in Mafikeng, South Africa. S Afr J Sci. 2014;110:1-9.

41. Maes S, Vackier T, Nguyen Huu S, Heyndrickx M, Steenackers H, Sampers I, et al. Occurrence and characterisation of biofilms in drinking water systems of broiler houses. BMC Microbiol. 2019;19:77.

42. Maharjan P, Clark T, Kuenzel C, Foy MK, Watkins S. On farm monitoring of the impact of water system sanitation on microbial levels in broiler house water supplies. J Appl Poult Res. 2016;25:266-71.

43. Mitri S, Foster KR. The genotypic view of social interactions in microbial communities. Annu Rev Genet. 2013:47:247-73.

44. Nadell CD, Drescher K, Foster KR. Spatial structure, cooperation and competition in biofilms. Nat Rev Microbiol. 2016;14:589.

45. Oblinger JL, Kraft AA. Inhibitory effects of Pseudomonas on selected Salmonella and bacteria isolated from poultry. J Food Sci. 1970;35:30-2.

46. Olanya OM, Sites JK, Hoshide AK. Cost modelling of Pseudomonas fluorescens and Pseudomonas chlororaphis as biocontrol for competitive exclusion of Salmonella enterica on tomatoes. Biocontrol Sci Tech. 2016;26: 651-64.

47. Pang $X$, Yang $Y$, Yuk H-G. Biofilm formation and disinfectant resistance of Salmonella spp. in mono- and dual-species with Pseudomonas aeruginosa. J Appl Microbiol. 2017:651-60.

48. Pang $\mathrm{X}$, Yuk H-G. Effect of Pseudomonas aeruginosa on the sanitizer sensitivity of Salmonella Enteritidis biofilm cells in chicken juice. Food Control. 2018:86:59-65.

49. Parijs I, Steenackers HP. Competitive inter-species interactions underlie the increased antimicrobial tolerance in multispecies brewery biofilms. ISME J. 2018;12:2061-75.

50. Pfeiffer T, Schuster S, Bonhoeffer S. Cooperation and competition in the evolution of ATP-producing pathways. Science (80- ). 2001;292:504-7.

51. Piccardi $P$, Vessman $B$, Mitri S. Toxicity drives facilitation between four bacterial species. bioRxiv. 2019;116(32):15979-84.

52. Rakoff-Nahoum S, Foster KR, Comstock LE. The evolution of cooperation within the gut microbiota. Nature. 2016:533:255-9.

53. Rendueles O, Ghigo JM. Ulti-species biofilms: how to avoid unfriendly neighbors. FEMS Microbiol Rev. 2012;36(5):972-89.

54. Roberts JA, Kruger P, Paterson DL, Lipman J. Antibiotic resistance-What's dosing got to do with it? Crit Care Med. 2008;36:2433-40.

55. Scholz RL, Greenberg EP. Sociality in Escherichia coli: Enterochelin is a private good at low cell density and can be shared at high cell density. J Bacteriol. 2015;197:2122-8.

56. Schonewille E, Nesse LL, Hauck R, Windhorst D, Hafez HM, Vestby LK. Biofilm building capacity of Salmonella enterica strains from the poultry farm environment. FEMS Immunol Med Microbiol. 2012;65:360-5.

57. Simões $L$, Simões $M$. Biofilms in drinking water: problems and solutions. RSC Adv. 2013;3:2520-33.

58. Soto SM, Smithson A, Horcajada JP, Martinez JA, Mensa JP, Vila J. Implication of biofilm formation in the persistence of urinary tract infection caused by uropathogenic Escherichia coli. Clin Microbiol Infect. 2006;12:1034-6.
59. Sparks NHC. The role of the water supply system in the infection and control of Campylobacter in chicken. Worlds Poult Sci J. 2009;65:459-74.

60. Steenackers H, Hermans K, Vanderleyden J, De Keersmaecker SCJ. Salmonella biofilms: an overview on occurrence, structure, regulation and eradication. Food Res Int. 2012;45:502-31.

61. Stepanović S, Vuković D, Dakić I, Savić B, Švabić-Vlahović M. A modified microtiter-plate test for quantification of staphylococcal biofilm formation. J Microbiol Methods. 2000;40(2):175-9.

62. Sun D, Zhuo T, Hu X, Fan X, Zou H. Identification of a Pseudomonas putida as biocontrol agent for tomato bacterial wilt disease. Biol Control. 2017;114:45-50.

63. Trachoo N, Frank JF, Stern NJ. Survival of Campylobacter jejuni in biofilms isolated from chicken houses. J Food Prot. 2016;65:1110-6.

64. van Asselt ED, Thissen JTNM, van der Fels-Klerx HJ. Salmonella serotype distribution in the dutch broiler supply chain. Poult Sci. 2009;88:2695-701.

65. Vandini A, Temmerman R, Frabetti A, Caselli E, Antonioli $P$, Balboni $P$, et al. Hard surface biocontrol in hospitals using microbial-based cleaning products. PLoS One. 2014;9:e108598.

66. van der Wielen PWJJ, Lut MC. Distribution of microbial activity and specific microorganisms across sediment size fractions and pipe wall biofilm in a drinking water distribution system. Water Sci Technol Water Supply. 2016;16: 896-904.

67. Van Eenige,MJEM, Counotte GHM, Noordhuizen JPTM. Drinking water for dairy cattle - Always a benefit or a microbiological risk? Tijdschr. Diergeneeskd. 2013;138:86-99.

68. Van Immerseel F, Meulemans L, De Buck J, Pasmans F, Velge P, Bottreau E, et al. Bacteria - host interactions of Salmonella Paratyphi B dT + in poultry. Epidemiol Infect. 2004;132:239-43.

69. Vestby LK, Møretrø T, Langsrud S, Heir E, Nesse LL. Biofilm forming abilities of Salmonella are correlated with persistence in fish meal- and feed factories. BMC Vet Res. 2009;5:20.

70. Wang $H$, Ye K, Zhang Q, Dong Y, Xu X, Zhou G. Biofilm formation of meatborne Salmonella enterica and inhibition by the cell-free supernatant from Pseudomonas aeruginosa. Food Control. 2013:32:650-8.

71. Zhao K, Li J, Huang T, Yuan Y, Lin J, Yue B, Wang X, Chu Y. Coexistence of microbial species in structured communities by forming a hawk-dove game like interactive relationship. Front Microbiol. 2019;10:807.

72. Zhao T, Podtburg TC, Zhao P, Schmidt BE, Baker DA, Cords B, Doyle MP. Control of Listeria spp. by competitive-exclusion bacteria in floor drains of a poultry processing plant control. Appl Environ Microbiol. 2006;72:3314-20.

73. Zhao T, Zhao P, Cannon JL, Doyle MP. Inactivation of Salmonella in biofilms and on chicken cages and preharvest poultry by levulinic acid and sodium dodecyl sulfate. J Food Prot. 2011;74:2024-30.

74. Zheng L, Zhou Y, Song K. Augmentative biological control in greenhouses: experiences from China. In: Second International Symposium on Biological Control of Arthropods; 2018. p. 538-45.

\section{Publisher's Note}

Springer Nature remains neutral with regard to jurisdictional claims in published maps and institutional affiliations.

Ready to submit your research? Choose BMC and benefit from:

- fast, convenient online submission

- thorough peer review by experienced researchers in your field

- rapid publication on acceptance

- support for research data, including large and complex data types

- gold Open Access which fosters wider collaboration and increased citations

- maximum visibility for your research: over $100 \mathrm{M}$ website views per year

At BMC, research is always in progress.

Learn more biomedcentral.com/submissions 